\title{
Quincas Borba: pretensão cosmopolita, detalhe popular
}

\author{
Homero Vizeu Araújo \\ (Universidade Federal do Rio Grande do Sul)
}

\begin{abstract}
RESUMO: ESTE ENSAIO TENTA EXAMINAR A TRAJETÓRIA DE RUBIÃO, NA CONDIÇÃO DE HOMEM LIVRE ERGUIDO A PROPRIETÁRIO NO SÉCULO DEZENOVE FICCIONAL RECRIADO EM QUINCAS BORBA, ROMANCE DE MACHADO DE ASSIS. AQUI SE ESTUDA TAMBÉM A ESTRATÉGIA NARRATIVA DE MACHADO PARA CARACTERIZAR, POR EXEMPLO, DONA TONICA, ESTRATÉGIA NARRATIVA QUE RESULTA EM AMBIGÜIDADE E DUPLICIDADE QUE REFLETEM A AMBIGÜIDADE DO ENREDO E DO TÍTULO DO ROMANCE, UMA VEZ QUE QUINCAS BORBA É O FILÓSOFO E TAMBÉM O NOME DE SEU CÃO.
\end{abstract}

ABSTRACT: THIS ESSAY TRIES TO EXAMINE THE PATH OF RUBIÃO, AS FREE MAN THAT BECAME CAPITALIST IN THE FICTIONAL NINETEENTH CENTURY OF QUINCAS BORBA, NOVEL BY MACHADO DE ASSIS. IT STUDIES, ALSO, THE NARRATIVE STRATEGY OF MACHADO TO SHOW THE CHARACTERISTICS OF, FOR INSTANCE, DONA TONICA, NARRATIVE STRATEGY THAT RESULTS IN AMBIGUITY AND DUPLICITY THAT REFLECT THE AMBIGUITY OF THE PLOT AND OF THE NOVEL TITLE, SINCE QUINCAS BORBA IS THE PHILOSOPHER AND THE NAME OF HIS DOG.

PALAVRAS-CHAVE: QUINCAS BORBA - MACHADO DE ASSIS - RUBIÃO - ROBERTO SCHWARZ

KEY-WORDS: QUINCAS BORBA - MACHADO DE ASSIS - RUBIÃO - ROBERTO SCHWARZ 
ês! Ninguém assistiu ao formidável

Enterro de tua última quimera.

Somente a Ingratidão - esta pantera -

Foi tua companheira inseparável!

Acostuma-te à lama que te espera!

O Homem, que, nesta terra miserável,

Mora, entre feras, sente inevitável

Necessidade de também ser fera.

(Augusto dos Anjos)

Caberia dar ênfase a um dado na abertura do romance Quincas Borba, de Machado de Assis. Rubião, o ingênuo provindo de Barbacena, contempla a baía da Guanabara a partir de sua mansão na praia de Botafogo. O detalhe é que Rubião goza a condição de capitalista depois de ter recebido o legado de Quincas Borba, personagem egresso do romance anterior de Machado de Assis, que se encerra com a afirmação enfática de ausência de legado a ser deixado por Brás Cubas. Depois de fazer o levantamento de negativas no encerramento de seu Memórias póstumas de Brás Cubas, vem a célebre frase:

E imaginará mal; porque, ao chegar a este outro lado do mistério, achei-me com um pequeno saldo, que é a derradeira negativa deste capítulo de negativas: - Não tive filhos, não transmiti a nenhuma criatura o legado da nossa miséria. (ASSIS, 1994: 152)

Se Brás Cubas não transmite seu legado, que é metafórico, Quincas Borba trata de fazê-lo e o beneficiário é o professor de meninos Rubião, que, desta forma, é guindado à condição de capitalista. Quem já leu o romance sabe que a riqueza vai ser também a condenação de Rubião, que será explorado e enganado por uns e outros até endoidar e retornar à pobreza. Neste sentido o legado, do qual deriva a desgraça de Rubião, torna-se assunto crucial do romance, como notou Antonio Candido em seu clássico Esquema de Machado de Assis: 
No romance Quincas Borba, um modesto professor primário, Rubião, herda do filósofo Quincas Borba uma fortuna, com a condição de cuidar de seu cachorro, ao qual dera o próprio nome. Mas com o dinheiro, que é uma espécie de ouro maldito, como na lenda dos Nibelungen, Rubião herda igualmente a loucura do amigo. A sua fortuna se dissolve em ostentação e no sustento de parasitas; mas serve sobretudo como capital para as especulações comerciais de um arrivista hábil, Cristiano Palha, por cuja mulher, "a bela Sofia”, Rubião se apaixona. $\mathrm{O}$ amor e a loucura surgem aqui romanticamente, de mãos dadas; mas o tertius gaudens é a ambição econômica, baixo-contínuo do romance, de que Rubião se torna um instrumento. No fim, pobre e louco, ele morre abandonado; mas em compensação, como queria a filosofia do Humanitismo, Palha e Sofia estão ricos e considerados dentro da mais perfeita normalidade social. (CANDIDO, 1995: 35)

$\mathrm{Na}$ síntese de Candido fica evidente que herança maldita, conjunto do enredo (casal Palha, especulação etc.) e humanitismo estão costuradíssimos, embora razoavelmente desnivelados na sua diversidade de, respectivamente, assunto literário quase clichê, caracterização psicossociológica e sátira filosófica. Enfim, Rubião só tem acesso ao legado e, digamos, à continuidade de Joaquim Borba dos Santos mediante o compromisso de velar pelo cachorro de Quincas Borba, que tem o mesmo nome de seu dono amalucado. E o filósofo é explícito: o cão é uma espécie de garantia de sua continuidade.

Uma das extravagâncias do dono foi dar-lhe o seu próprio nome; mas, explicava-o por dois motivos, um doutrinário, outro particular.

- Desde que Humanitas, segundo a minha doutrina, é o princípio da vida e reside em toda a parte, existe também no cão, e este pode assim receber um nome de gente, seja cristão ou muçulmano...

- Bem, mas por que não lhe deu antes o nome de Bernardo, disse Rubião com o pensamento em um rival político da localidade.

- Esse agora é o motivo particular. Se eu morrer antes, como presumo, sobreviverei no nome do meu bom cachorro. Ris-te, não?

Rubião fez um gesto negativo.

- Pois devias rir, meu querido. Porque a imortalidade é o meu lote ou o meu dote, ou como melhor nome haja. Viverei perpetuamente no meu grande livro. 
Os que, porém, não souberem ler, chamarão Quincas Borba ao cachorro, e... (ASSIS, 1980: 16)

No título do livro, o nome do filósofo demente e o nome do cachorro coincidem, e no encerramento do romance a indiferença entre cão e filósofo é assunto de meditação do narrador. O jogo de espelhos dá ênfase à duplicidade do título, mas a duplicidade é recorrente ao longo do romance. A narrativa, diga-se, encontra-se eivada de ambivalências e dubiedades que vão desde a caracterização do auto-engano contínuo de personagens cruciais como Rubião e Sofia até a suspeita do adultério entre Sofia e o enfatuado Carlos Maria, à qual nós, leitores desavisados, somos levados para sermos quase ridicularizados pelo perverso narrador. As seqüências e situações que exploram a duplicidade não cessam de se apresentar, o que define um procedimento que será reelaborado ao máximo em Dom Casmurro, de acordo com Roberto Schwarz: "O virtuosismo de Machado na invenção de assuntos e seqüências que dêem realce à dualidade do narrador chega ao inacreditável.” (SCHWARZ, 1997: 36). Sem mencionar Esaú e Jacó, cuja duplicidade é enunciada já no título.

A piada patética é que o cão Quincas Borba, depois da morte do filósofo, está sempre levando pancada, o que não deixa de ser um comentário sobre a posteridade e a perpetuação da palavra e da filosofia do pensador Quincas Borba. De uma narrativa que se encerra com a ausência de legado de Brás Cubas, deriva o romance cujo tema material, digamos, é a dilapidação contínua de um legado; a dilapidação da herança deixada por Quincas Borba para Rubião.

Trata-se de um romance narrado em terceira pessoa, o que é uma raridade na segunda fase de Machado de Assis. Diga-se que os trejeitos do narrador machadiano permanecem aqui, com o narrador irônico e digressivo comentando os dados miúdos do cotidiano brasileiro com humor e distanciamento. Mas os trejeitos não estão a serviço de um narrador em primeira pessoa inventivo e patife, um tanto apalhaçado como Brás Cubas. Inventivo, patife e volúvel, na célebre tese de Roberto Schwarz, defendendo que Machado mimetiza e reelabora os procedimentos da elite brasileira, burguesa e escravista, pretensamente cidadã e objetivamente privilegiada, defendendo seus privilégios com argumentos supostamente avançados. Na voz de Brás Cubas teríamos revelação e autodesvendamento, os quais dependem da enorme sofisticação da cultura de elite para funcionar. 
Já o narrador em terceira pessoa de Quincas Borba parece ter uma margem de manobra mais restrita e nos apresenta a trajetória de um despretensioso professor primário que, mediante golpe de sorte, vira capitalista, para, na condição de ricaço ingênuo, vir a ser sangrado por uma chusma de parasitas. Enquanto Brás Cubas é um cínico que inclusive já morreu quando começa seu relato, Rubião é um ingênuo, quase um pateta, que nada entende dos negócios em que anda metido.

Pior, Brás Cubas teoriza e faz piada com seus delírios compensatórios ou suas ilusões de auto-engano, enquanto as digressões do narrador de Quincas Borba, também denunciando e ironizando a imaginação compensatória e o auto-engano do parvo Rubião, não permitem a auto-ironia, incidindo na caracterização satírica irremediável não só de Rubião, mas principalmente dos interesseiros que o circundam. Isto é, Machado de Assis, autor que se confunde ao narrador, monta uma condenação satírica implacável do circuito chique do Rio de Janeiro oitocentista, apresentado como uma corja de parasitas. E o resultado estético se ressente deste procedimento, que pode ganhar caráter um tanto mecânico e óbvio ao longo dos capítulos. Uma hipótese é que o típico narrador humorístico e irônico em primeira pessoa de Machado sempre é mais ou menos auto-acusatório, logo, o único romance humorístico em terceira pessoa teria perdido esta dimensão, que dá gume às reflexões de Brás Cubas, Bento Santiago e Conselheiro Aires.

Por outro lado, estes narradores, que são também protagonistas machadianos típicos, são respeitáveis representantes da elite brasileira, e Rubião não é um burguês escravocrata de nascença, ele é um homem livre, isto é um despossuído que se agrega à casa de Quincas Borba para prestar serviços de enfermeiro, sempre sonhando com algum tipo de retribuição na herança. Ora, enquanto a elite pode aderir aos procedimentos de auto-engano para na seqüência denunciá-los cinicamente ou manipulá-los para seus fins, um tipo como Rubião, homem livre na ordem escravocrata, deixa-se levar pelos delírios compensatórios até virar, literalmente, um Napoleão de hospício. Tudo isso sob o olhar entre melancólico e sarcástico do narrador machadiano que se compraz em dissecar as marchas e contramarchas da consciência (e inconsciência) de um pobre diabo, de um ex-agregado que não tem mais a quem se agregar, sem ter também as condições mínimas para agregar o próximo. Destinado, neste sentido, ao limbo das almas nem servis nem servidas, o que 
paradoxalmente seria uma definição de cidadania em uma sociedade em que tal categoria fizesse sentido, um lugar sem dúvida longe do Império escravista tropical, do Brasil brasileiro que vai dar samba no século XX.

Estaríamos diante do romance de um homem pobre enriquecido em uma sociedade em que riqueza se articula a uma mascarada de domínio público, mas de uso privado, do qual Rubião está excluído. Um jogo cujas regras ele sequer intui, e menos ainda domina. Uma espécie de José Dias que não tem a quem adular, quase uma impossibilidade ontológico no Brasil oitocentista, configurando uma existência que evolui com alguma graça e muita desgraça para o manicômio e a morte.

Mero acaso que o único romance de Machado maduro que tem por protagonista um homem livre tenha este andamento? Acho que não. E John Gledson, na introdução de Fiç̧ão e história arrisca uma interessante caracterização do procedimento narrativo de Quincas Borba:

Na superfície, a trama tem muito pouco a ver com grandes questões históricas, mas existe aqui uma intensa ironia, porque Machado simplesmente - e, em certo sentido, de maneira realista - decidiu adotar o ponto de vista de personagens como Palha, para quem as questões radicais têm pouca importância, e apresentar as questões reais através do veículo distorcido da loucura de Rubião. (GLEDSON, 1986: 22)

No mundo tropical escravocrata, a perspectiva que rende narrativa longa e orgânica é a de cima, da elite, daí o acerto de tom de Machado ao explorar em grande escala tal perspectiva. Já o exame impiedoso do sacrifício de Rubião no altar das vaidades da metrópole negreira carioca é quase uma demonstração da ausência de um ponto de vista alternativo ou, então, de uma visão de mundo capaz de se contrapor ao cinismo escravista disseminado. Assim, o ponto de vista de personagens como Palha ou Camacho, com a distância da terceira pessoa, resultaria em um relato menos realizado que o dos narradores protagonistas Cubas, Bentinho e Aires.

Se analisarmos o caráter documental de Quincas Borba, há um razoável volume de informações sobre trabalho intelectual e mais ou menos especializado aqui. Rubião, digamos, é homem livre na ordem escravocrata, erguido à condição de proprietário, isto é, de senhor de escravos, embora ele venha a 
se livrar de seus cativos na primeira oportunidade que tem, o que está dito no trem rumo ao Rio durante o primeiro encontro com o casal Palha.

Já Palha encerra o romance sonhando um título nobiliárquico para Sofia, mas trabalha duro durante todo o relato. Quando trata de devolver a Rubião o que lhe cabe da sociedade que fundaram, Palha já tem em vista tornar-se banqueiro. Mas antes disso o burguês matreiro que explorou o capital mais ou menos ocioso de Rubião já demonstrara sua capacidade de trabalho e dedicação no cais do porto, ao que tudo indica em uma empresa de exportação e importação. Vale lembrar que o tráfico escravista, na segunda metade do século XIX, deixara de ser a grande atividade lucrativa da sociedade brasileira.

Palha, neste sentido, é o anti-Brás Cubas, o protagonista do romance anterior, que jamais é apresentado tocando um negócio e parece só administrar seus bens e rendas. Está certo, Palha é um burguês arrivista, representado em sua ascensão, enquanto Cubas nasceu em berço de ouro escravocrata.

Outro anti-Cubas é Camacho, advogado formado em Recife, jornalista e político por vocação. Este é um parasita agressivo, que dilapida os bens de Rubião para sustentar a Atalaia, seu jornal político de oposição (e de conciliação), redigido com um amontoado de lugares-comuns, clichês que Machado trata de documentar com disposição satírica razoavelmente minuciosa. Mas esse parasita trabalha honestamente como advogado; e nos seus lazeres, que constituem sua razão de viver, trata de encaminhar a política cabível. O narrador de Machado deixa claro que Camacho mantém sua advocacia de forma honrada para garantir sustento e alguma ostentação, mas sua banca de advogado também permite a intervenção na esfera política. Com o patrocínio de Rubião, Camacho não ganha maior relevância política, embora provavelmente seu jornal tenha maior repercussão.

Importante é que tanto Camacho quanto Palha são exemplos de operosidade e dedicação burguesa no pólo oposto aos procedimentos de Brás Cubas, ocioso descarado e mais ou menos canalha. Assim sendo, Machado está desvendando o lado burguês da capital carioca. Palha, burguês ambicioso que trata de derivar para as finanças e sonhar com título nobiliárquico; Camacho, advogado medíocre ou mediano com paixão pelo debate político (críticas à guerra do Paraguai e à lei dos Ingênuos/Ventre Livre).

E no 'pega para capar' generalizado, Rubião é o ingênuo que não conhece as regras do jogo, nem do jogo da sedução perpetrado por Sofia (sedução e 
ostentação burguesa, fique claro), nem o jogo capitalista da preservação e ampliação do patrimônio, com suas despesas e receitas. Ele que era um dependente, um homem livre pobre, candidato a cunhado, depois enfermeiro agregado de Quincas Borba. Pois agora ele caiu dentro de uma feroz arena de disputas, em que a sobrevivência do mais forte ou mais adaptado é lei geral. Isto é, Rubião torna-se vítima da lei que enunciava sem conhecer seu significado; Darwin versão Spencer, mediante síntese biruta de Quincas Borba: ao vencedor, as batatas.

Ao vencido que é Rubião, alguma compaixão ou ódio, tal como na fábula enunciada pelo filósofo pancada Quincas Borba no capítulo VI. Capítulo em que se refere também D. Quixote, livro brandido por Quincas Borba.

Ao vencido, ódio ou compaixão; ao vencedor, as batatas.

- Mas a opinião do exterminado?

- Não há exterminado. Desaparece o fenômeno; a substância é a mesma. Nunca viste ferver a água? Hás de lembrar-te que as bolhas fazem-se e desfazem-se de contínuo; e tudo fica na mesma água. Os indivíduos são essas bolhas transitórias.

- Bem; a opinião da bolha...

- Bolha não tem opinião. Aparentemente, há nada mais constritador que uma dessas terríveis pestes que devastam um ponto do globo? E todavia, esse suposto mal é um benefício, não só porque elimina os organismos fracos, incapazes de resistência, como porque dá lugar à observação, à descoberta da droga curativa. A higiene é filha de podridões seculares; devemo-la a milhões de corrompidos e infectos. Nada se perde, tudo é ganho. Repito, as bolhas ficam na água. Vês este livro? É Dom Quixote. Se eu destruir o meu exemplar, não elimino a obra que continua eterna nos exemplares subsistentes e nas edições posteriores. Eterna e bela, belamente eterna, como este mundo divino e supradivino. (ASSIS, 1980: 19)

A referência ao Quixote antecipa a trajetória e demência de Rubião, que armado de idéias românticas investe contra a bela Sofia, que o engambela e trata de explorar, retirando daí razoável prazer erótico. Talvez toda a fantasia sobre adultério entre Sofia e Carlos Maria, que está no miolo do livro, venha a constituir um artefato literário/moinho de vento montado para expor a ilu- 
são e a tolice do ignaro Rubião e do leitor. No caso de Rubião, é praticamente aí que é deflagrado o processo de alienação que culminará em um Napoleão de hospício. Rubião e leitor são levados pelas evidências de mistério folhetinesco e acabam com cara de bobos, para prazer (perverso?) do narrador.

Além do mais, são ideais românticos e altruístas que levam Rubião a distribuir dinheiro para Camacho e outros parasitas. E, no esforço de busca de uma supremacia qualquer, levam o personagem a se identificar com Luís Napoleão, quando se chega a certo estágio avançado da doença. Ou será que Rubião acredita no mito do patriarcalismo gentil, ficção de homem livre/ agregado. Acreditaria na cordialidade desinteressada (versão bonachona de Sérgio Buarque)? Mas aqui o arbítrio e a veleidade são privilégios que não se permitem à manutenção do dinheiro e patrimônio, pelos quais cabe zelar ferozmente. Rubião trata de garantir a adesão afetiva e a admiração mediante desperdício desvairado, comportando-se como patriarca imprevidente. Um homem cordial tolo que saca dos bens privados para se candidatar ao bem público, quando a lição cordial patrimonialista reza o contrário: sacar dos bens públicos a favor do patrimônio privado.

Machado, ao estudar os métodos e meios da sociedade que se aburguesa (Palha, Camacho, mesmo o honrado Teófilo), expõe, por contraste, os trejeitos e impasses de Rubião que não domina a nova regra em ascensão e se deixa levar pela fantasia aristocrática/benevolente/paternalista que é a versão oficial e auto-imagem do Império Brasileiro, oposta à prática mercantil-escravista que dava as ordens.

Sem ter a quem servir, e incapaz de ser servido, Rubião serve a Sofia, com adulações e presentes, e depois servirá sua auto-imagem, a projeção ensandecida de sua personalidade em Napoleão III. O ex-agregado não sabe o que fazer com sua liberdade de proprietário endinheirado.

Já para Major Siqueira, figura do círculo inicial de Palha, a questão é outra. $\mathrm{Na}$ condição de militar aposentado, funcionário público um tanto desqualificado, ele em breve será descartado por Palha; logo Siqueira, que foi testemunha um tanto desastrado do encontro de Rubião e Sofia no jardim. O major também é um homem livre na ordem oligárquica, mas uma vez abandonado por Palha, trata de exprimir seu ressentimento em relação ao antigo amigo. O major não perde a noção da realidade e por isso mesmo trata de enunciar seu ressentimento, que também não é muito amargo, embora bem marcado 
e definido na relação com sua filha, Dona Tonica. Ao passo que em Rubião e, noutro caso clássico da literatura brasileira, em Policarpo Quaresma, o que desponta é a mania, ou, no limite, a loucura.

Até que ponto se mantém a volubilidade do narrador que era tão saliente em Memórias póstumas? Naquele livro a volubilidade dependia do arbítrio e dos vaivéns da consciência de Brás Cubas. Aqui, em Quincas Borba, este processo está bloqueado pelo narrador em terceira pessoa, que se propõe a acompanhar a ruína mental e material de Rubião. Sendo assim, os trejeitos e ironia do narrador de Machado expõem e reexpõem a teoria da exploração compulsória, da competição compulsiva ditada pelo filósofo Quincas Borba: ao vencedor as batatas. Oscilando, diga-se, entre a anotação detalhada do ambiente brasileiro e o comentário cosmopolita/filosófico. É argumentável que tal procedimento do narrador rende algo da volubilidade de Cubas.

O cotidiano mesquinho/diminuído é iluminado pela comparação mitológica, isto é, pelo raciocínio generalizante que está em evidência já no lema e frase exemplar de Quincas. Ao vencedor, segundo Darwin e Spencer em versão tropicalista, cabem as batatas. Como se a batalha árdua da civilização tivesse objetivo tão mesquinho e rebaixado. Vale lembrar que, na virada do século XIX para XX, Machado não se encontra só no procedimento literário que mistura ambição filosófica e detalhe mesquinho nacional; penso que algo parecido se manifesta na poesia de Augusto dos Anjos, em que o raciocínio evolucionista é revertido para dar conta, com humor negro, do urubu que pousou na sorte do poeta.

No capítulo 43, Dona Tonica, é a madurona filha de Siqueira, o aborrecido major. Dona Tonica percebeu a corte que Rubião fizera à bela Sofia e amarga a indiferença de Rubião e o ciúme da empreitada toda. Ela, Tonica, é solteirona à beira do desespero pela ausência de pretendentes. Tonica remói seu ressentimento:

Não trazia idéias de paz nem de candura. Sem conhecer o amor, tinha notícia do adultério, e a pessoa de Sofia pareceu-lhe hedionda. Via nela agora um monstro, metade gente, metade cobra, e sentiu que a aborrecia, que era capaz de vingar-se exemplarmente, de dizer tudo ao marido. (ASSIS, 1980: 49)

E o narrador prossegue escalpelando as auto-ilusões e a fúria de Dona Tonica, que num primeiro momento se dispõe a tudo dizer a Palha sobre o interlúdio de 
Rubião e Sofia. A “explosão de raiva interior” inclui a imaginação compensatória de uma cena em que Palha humilharia furiosamente Sofia, a pérfida.

Na seqüência, a "alma cansou, e tornou a si", e temos a cena de D. Tonica contemplando a pobreza de seu quarto arrumadinho, com paredes tristes etc. Mas o parágrafo de descrição realista encerra com o tom bíblico, talvez do Cântico dos cânticos: "E tudo ali parecia feito para receber um novo amado." (ASSIS, 1980: 50).

E o parágrafo seguinte prossegue no âmbito bíblico acompanhado pela dúvida do narrador: "Onde li eu que uma tradição antiga fazia esperar a uma virgem de Israel, durante certa noite do ano, a concepção divina? Seja aonde for, comparemo-la à desta outra, que só difere daquela em não ter noite fixa..." (ASSIS, 1980: 50). E Machado persevera misturando a provocação à poesia. A provocação vai pelo argumento enviesado de que há equivalência entre as virgens de Israel e a pobre Tonica, as virgens bíblicas e a encruada virgem carioca filha do malicioso e ressentido pobretão major Siqueira. Machado usa até a repetição "todas, todas, todas" para enfatizar o desespero e o desamparo da pobre Tonica, virgem de Israel abandonada no Rio de Janeiro, cujo vento nunca lhe trouxe o varão esperado etc. Ou seja, a retórica bíblica e poética prossegue caracterizando a ressentida Tonica, que amarga uma solteirice carioca a contrastar com os dilemas bíblicos. A poesia faz contraponto irônico ao último parágrafo do capítulo que retoma e resume a longa espera do noivo agravada pelo sucesso relativo das amigas que casaram.

Agora, aquietada a imaginação e o ressentimento, mira e remira a alcova solitária; recorda as amigas do colégio e de família, as mais íntimas, casadas todas. A derradeira delas desposou aos trinta anos um oficial de marinha, e foi ainda o que reverdeceu as esperanças à amiga solteira, que não pedia tanto, posto que a farda de aspirante foi a primeira coisa que the seduziu os olhos, aos quinze anos... Onde iam eles? Mas lá passaram cinco anos, cumpriu os trinta e nove, e os quarenta não tardam. Quarentona, solteirona: Dona Tonica teve um calafrio. Olhou ainda, recordou tudo, ergueu-se de golpe, deu duas voltas e atirou-se à cama chorando... (ASSIS, 1980: 50)

O parágrafo-resumo é uma pequena obra-prima de síntese de Machado, que repele os detalhes realistas para incidir na passagem dos anos, com notícia breve sobre a primeira atração da Tonica, ainda adolescente, pela farda 
militar. A última frase do capítulo está enfaticamente longe da poesia bíblica e elevada para dar voz à poesia preconceituosa e popular: "Quarentona, solteirona; Dona Tonica teve um calafrio. Olhou ainda, recordou tudo, ergueu-se de golpe, deu duas voltas e atirou-se à cama chorando..."

Assim o resumo sintético mas espichado encerra-se com a referência popular que é próxima do mundo mental de Dona Tonica, o que denuncia quão distante de consolo é a referência bíblica e erudita introduzida pelo narrador. Narrador bíblico erudito, mas Dona Tonica chorando atirada na cama sentindo (ouvindo?) o refrão popular.

Ao comentar outro trecho de Quincas Borba, Roberto Schwarz fez a síntese do que tentamos demonstrar aqui.

Em Quincas Borba, o leitor a todo momento encontra, lado a lado e bem distintos, o "local" e o "universal". A Machado não interessava a sua sintese, mas a sua disparidade, a qual lhe parecia característica. Seria, para usar as suas palavras, um dos "assuntos que lhe oferecia a sua região"? Nesta convivência irreconciliada, em que se pode ver cifra de uma situação histórica e cultural, os termos se ridicularizam reciprocamente. Aliás, a própria fixação enfática destes níveis, a ponto de se tornarem planos retóricos distintos, já é um recurso cômico, algo como um registro de alienação. (SCHWARZ, 1989: 170)

O próximo capítulo de Quincas Borba, o 44, traz o comentário implacável e irônico do narrador que remói os sentimentos da pobre Tonica. Uma pobretona pela qual o narrador tem um interesse notável, o que fala a favor da complexidade dos personagens pobres de Machado. Pesando e repesando os vaivéns da consciência atormentada de Tonica, o narrador encerra o curto capítulo que é só um parágrafo. Machado compara agora a gentil Tonica com Calígula (!!!??), o que é quase um disparate, mas que retoma o dado erudito da Bíblia citada anteriormente. Tonica, depois de comparada a virgens de Israel, ganha louros de Calígula. Uma intervenção do narrador que, no conjunto do relato, contrasta e ilumina a identificação do pobre Rubião com Napoleão III: dois ressentidos que são comparados a imperadores. Assim, versões e ilusões que se sucedem configuram um artifício recorrente ao longo da narrativa.

Como se não bastasse, depois da caracterização imperial de Dona Tonica vem o capítulo 45 , com o prosseguimento do comentário do narrador, que 
abandona a comparação com Calígula e inicia o paralelo entre Tonica com Rubião, cuja alma ri. E a comparação entre Rubião e Tonica sai enfática e filosofante, no limite da bobagem pensamentosa.

Enquanto uma chora, outra ri, é a lei do mundo, meu rico senhor; é a perfeição universal. Tudo chorando seria monótono, tudo rindo cansativo; mas uma boa distribuição de lágrimas e polcas, soluços e sarabandas, acaba por trazer à alma do mundo a variedade necessária, e faz-se o equilíbrio da vida. (ASSIS, 1980: 51)

No inicio dos anos 70 do século XX, tal filosofia será cantada por Tim Maia em É primavera: um nasce para chorar, enquanto o outro ri. Como talvez notasse John Gledson, uma filosofia mediana e individualista que poderia fazer parte do arsenal burguês do ambicioso e pragmático Palha, sem mencionar que se trata de mais uma versão de lema de Quincas Borba: ao vencedor as batatas.

Ou será só um momento menos inspirado do narrador irônico machadiano? Um trecho que incorpora o ceticismo bem-pensante de Anatole France, digamos. Afinal, em Brás Cubas, por exemplo, a ironia mais apalhaçada perdia o tom mórbido e melancólico mais óbvio, além de incluir certo esnobismo feroz que se afasta do senso comum. Aqui, entre Tonica e Rubião, o narrador parece se comprazer em expor o nervo das ilusões, ressentimentos, compensações imaginárias etc. dos iludidos sem que ocorra a autocrítica, já que o ponto de vista do narrador é superior e distanciado.

A tirada filosofante da alma que chora enquanto a outra ri vem na abertura da seqüência que desaguará na memória da execução do preto por outro preto, na famosa cena do enforcamento público em Quincas Borba. Trata-se de uma passagem razoavelmente enigmática do romance, romance em que raramente aparecem escravos. Eles são praticamente ausentes, até como pano de fundo doméstico. E no enforcamento os dois negros comparecem no centro da cena, literalmente no centro das atenções, verdadeiras estrelas neste espetáculo macabro da execução pública. Vale lembrar que é um espetáculo público gratuito, assim como a missa e as procissões religiosas, no Rio de Janeiro da juventude de Rubião.

Mas muito antes da cena do patíbulo, logo depois da reflexão sobre as lágrimas de um e riso de outro, temos as dúvidas de Rubião sobre prosseguir na abordagem de Sofia, abordagem que, bem sucedida, desaguaria em traição 
e adultério, ou ainda as dúvidas prosaicas sobre qual tílburi tomar para voltar para casa em Botafogo. Destas duas dúvidas brota a memória da cena do enforcamento e a memória da antiga dúvida: seguir ou não a multidão que vai assistir ao enforcamento. E atrás do enforcamento só não vai quem já morreu. O fato é que as dúvidas de Rubião não o impedem de seguir o enforcamento e ter o piripaque/desmaio no meio da multidão, depois que o preto verdugo cavalga o preto condenado. De dúvida para dúvida, o encerramento é na casa de Rubião, com a dubiedade/duplo Quincas Borba cão ou filósofo. Ali Rubião especula sobre a possível metempsicose de Rubião filósofo em seu cão homônimo. Sendo assim, a ambigüidade que está no título do romance ecoa o feroz e paródico Ao vencedor as batatas novamente. Em chave dúbia e meditativa, teríamos o desenlace da cena da execução: ao vencedor a cavalgada, ao vencido ser cavalgado na forca. Esta seria uma possível versão da execução sob a lente do filósofo que teria reencarnado no cachorro.

Repassando a cena do ponto de vista estrutural - e tudo está muito costurado no conjunto - temos a escolha entre assistir à morte ou não, dilema do jovem Rubião, e a escolha do rico e maduro Rubião no presente que vacila entre avançar sobre Sofia ou não, embarcar em um tílburi ou outro. Oscilação e dubiedade que refratam a duplicidade que está no título, o filósofo Quincas Borba, reencarnado em cachorro (perro del infierno, segundo o gentil criado castelhano). Mas a transmigração das almas é crença adquirida por influência de uma preta de São João d'El Rei.

Foi uma preta de São João d'El Rei que lhe meteu, em criança, essa idéia de transmigração. Dizia ela que a alma cheia de pecados ia para o corpo de um bruto; chegou a jurar que conhecera um escrivão que acabou como gambá...

- Vossa Senhoria não se esqueça de dizer onde é a casa, disse-lhe repentinamente o cocheiro.

- Pare. (ASSIS, 1980: 55)

Em outras palavras, a crendice popular daquela preta da infância relativiza as pretensões à imortalidade que levaram o filósofo a batizar o cão. Voltamos à fórmula que oscila entre a pretensão filosofante e cosmopolita e o detalhe popular e realista, com o adensamento da complexidade literária ao se fazer referência ao duplo e a dubiedades várias no enredo intrigante e intrincado do romance. 


\section{Referências Bibliográficas}

ASSIS, Joaquim Maria Machado de. Memórias póstumas de Brás Cubas. São Paulo: Moderna, 1994 (Coleção Travessias).

- Quincas Borba. São Paulo: Ática, 1980 (Série Bom Livro).

CANDIDO, Antonio. Esquema de Machado de Assis. In: Vários escritos. 3. ed. revista e ampliada. São Paulo: Duas Cidades, 1995.

GLEDSON, John. Machado de Assis: fição e história. Rio de Janeiro: Paz e terra, 1986.

SCHWARZ, Roberto. Duas notas sobre Machado de Assis. In: Que horas são? São Paulo: Companhia das Letras, 1989.

Duas meninas. São Paulo: Companhia das Letras, 1997.

. Um mestre na periferia do capitalismo. São Paulo: Duas Cidades, 1990. 